\title{
The effects of alternate irrigation of root canals with chelating agents and sodium hypochlorite on the effectiveness of smear layer removal
}

\author{
Wojciech Wilkoński, ${ }^{1, A-D}$, Lidia Jamróz-Wilkońska ${ }^{2, A, C, D}$, Szczepan Zapotoczny3,B,C, \\ Janusz Opiła ${ }^{4, B, C}$, Jerzy Krupiński ${ }^{5, E, F}$, Jolanta Pytko-Polończyk ${ }^{6, A, E, F}$ \\ ${ }^{1}$ Research Department of the Polish Endodontic Society, Kielce, Poland \\ 2 Private dental office, Wadowice, Poland \\ ${ }^{3}$ Department of Physical Chemistry and Electrochemistry, Jagiellonian University, Kraków, Poland \\ ${ }^{4}$ Department of Applied Computer Science Faculty of Management, AGH University of Science and Technology, Kraków, Poland \\ ${ }^{5}$ Retired Professor of the Medical University of Silesia, Katowice, Poland \\ ${ }^{6}$ Department of Integrated Dentistry, Dental Institute, Faculty of Medicine, Jagiellonian University Medical College, Kraków, Poland \\ A - research concept and design; B - collection and/or assembly of data; C - data analysis and interpretation; \\ $D$ - writing the article; $E$ - critical revision of the article; $F$ - final approval of the article
}

Address for correspondence

Wojciech Wilkoński

E-mail:wilkonski@onet.eu

\section{Funding sources}

The research was carried out with equipment purchased thanks to the financial support of the European Regiona Development Fund, within the framework of the Polish Innovation Economy Operational Program (contract No. POIG.02.01.00-12-023/08).

Conflict of interest

None declared

Received on November 1, 2017

Reviewed on June 21, 2019

Accepted on September 25, 2019

Published online on February 26, 2020

Cite as

Wilkoński W, Jamróz-Wilkońska L, Zapotoczny S, Opiła J, Krupiński J, Pytko-Polończyk J. The effects of alternate irrigation of root canals with chelating agents and sodium hypochlorite on the effectiveness of smear layer removal. Adv Clin Exp Med. 2020;29(2):209-213.

doi:10.17219/acem/112603

DOI

10.17219/acem/112603

\section{Copyright}

Copyright by Author(s)

This is an article distributed under the terms of the

Creative Commons Attribution 3.0 Unported (CC BY 3.0)

(https://creativecommons.org/licenses/by/3.0/)

\section{Abstract}

Background. After the mechanical preparation of a root canal, the canal walls are covered with a smear layer. In order to deeply clean the dentinal tubules, removal of the smear layer is recommended. There is no consensus on the length of time of rinsing with chelating agents or irrigation with alternating chelating agents and sodium hypochlorite ( $\mathrm{NaOCl}$ ).

Objectives. The aim of the study was to evaluate the effectiveness of smear layer removal using 4 irrigation protocols.

Material and methods. We prepared 42 straight root canals to size ISO40/04 and assigned them into 4 study groups $(n=10)$ and a control group $(n=2)$. The root canals were irrigated as follows: in the control group, 180 s with $5.25 \% \mathrm{NaOCl}$; in group 1, 60 s with $40 \%$ citric acid (CA) and $120 \mathrm{~s}$ with $\mathrm{NaOCl}$; in group 2, $120 \mathrm{~s}$ with CA and $120 \mathrm{~s}$ with $\mathrm{NaOCl}$; in group 3, 30 s CA, 30 s with $\mathrm{NaOCl}, 30 \mathrm{~s}$ CA and 120 s with NaOCl; and in group 4,60 s with CA, $30 \mathrm{~s}$ with $\mathrm{NaOCl}, 60 \mathrm{~s}$ with $\mathrm{CA}$, and $120 \mathrm{~s}$ with $\mathrm{NaOCl}$. The roots were split longitudinally and the root canals were observed under $\times 200-500$ magnification. The root canal walls were analyzed in areas $2 \mathrm{~mm}, 6 \mathrm{~mm}$ and $10 \mathrm{~mm}$ from the apex.

Results. In the apical and medial sections, the best effects were achieved in groups 3 and 4 . In coronal sections, no significant differences between experimental groups were found.

Conclusions. Within the limitations of this study, it can be concluded that irrigation with alternating $\mathrm{NaOCl}$ and $C A$ was the most effective at smear layer removal, regardless of the irrigation time.

Key words: irrigation, citric acid, sodium hypochlorite, smear layer, root canals 


\section{Introduction}

The effects of endodontic treatment depend mainly on decontamination and complete obturation of the root system of the teeth. ${ }^{1-10}$ During the mechanical preparation of root canals, a smear layer is created..$^{1-7}$ Its role in endodontic treatment is still debated. The smear layer is composed of inorganic components (water and dentin debris), as well as organic components (pulp remnants, collagen, bacteria). It covers the dentin surface and clogs the dentinal tubules. It is supposed that the smear layer should be removed after the mechanical preparation of root canals, because the sealing effect of canal obturation can be marred as a result of changes in the volume of the smear layer, and because the smear layer prevents access to the dentinal tubules, where pathogens can be located. ${ }^{6-8}$ Dissolution of the smear layer opens the dentinal tubules and increases the permeability of dentin, as a result of which antiseptic solutions and sealers can penetrate the dentinal tubules to neutralize and seal in microorganisms. ${ }^{8}$

Sodium hypochlorite $(\mathrm{NaOCl}$; for the dissolution of organic components) and chelating agents (for the dissolution of inorganic components) are used to remove the smear layer. Commonly used chelating agents include EDTA (in the form of disodium salt of ethylenediaminetetraacetic acid) and citric acid (CA). Usually a 17\% solution of EDTA and $20 \%$ or $40 \%$ solutions of CA are used; $17 \%$ EDTA has similar chelating properties to $20 \%$ CA. ${ }^{9,10}$

Most studies on removal of the smear layer are based on scanning electron microscopy (SEM). These tests are very expensive, and are flawed due to the method of specimen preparation. ${ }^{1,2,6}$ Thanks to the development of optical microscopy and digital image processing, it is possible to obtain sharp microphotographs in $\times 500-1000$ magnification without the need for physical and chemical processing of the specimens. Despite numerous studies, the exact concentration, time and sequence of application of irrigating liquids for optimal removal of the smear layer is still not known. ${ }^{3,4,9}$ The null hypothesis for this study assumes that better effectiveness of smear layer removal will be achieved in canals irrigated with a chelating agent for a longer period. The aim of the study was a comparative analysis of the effectiveness of smear layer removal using 4 proposed irrigation protocols.

\section{Material and methods}

In the study, we used 42 human upper incisors extracted for periodontal reasons. The extracted teeth were stored in $1 \%$ solution of chloramine. The anatomical crowns were resected using drills with diamond coating under constant water-air cooling. The working length was determined using size $10 \mathrm{C}$-files (VDW GmbH, Munich, Germany) to reach the anatomical foramen, then deducting $0.5 \mathrm{~mm}$ from the obtained length. Root canals were prepared using
Reciproc 25 and 40 instruments with a Silver Reciproc endodontic micromotor (all from VDW GmbH). The canals were then calibrated using size $40 \mathrm{~K}$-files (VDW). Each tool was covered with a small amount of FileCare lubricant (VDW GmbH) before insertion into the canal, and between the cycles, the canals were irrigated with $5.25 \%$ $\mathrm{NaOCl}$. After the preparation of the root canals, the root apexes were sealed with sculpting wax to avoid any overflow of liquids through the apexes. The roots were then randomly divided into 4 equal study groups $(n=10)$ and a control group $(n=2)$. The canals were irrigated according to the following protocols:

- control group: $5.25 \% \mathrm{NaOCl}-180 \mathrm{~s}$;

- group 1:

$40 \% \mathrm{CA}-60 \mathrm{~s}$,

$5.25 \% \mathrm{NaOCl}-120 \mathrm{~s}$;

- group 2:

$40 \% \mathrm{CA}-120 \mathrm{~s}$,

$5.25 \% \mathrm{NaOCl}-120 \mathrm{~s}$;

- group 3:

$40 \% \mathrm{CA}-30 \mathrm{~s}$,

$5.25 \% \mathrm{NaOCl}-30 \mathrm{~s}$,

$40 \% \mathrm{CA}-30 \mathrm{~s}$,

$5.25 \% \mathrm{NaOCl}-120 \mathrm{~s}$;

- group 4:

$40 \% \mathrm{CA}-60 \mathrm{~s}$,

$5.25 \% \mathrm{NaOCl}-30 \mathrm{~s}$,

$40 \% \mathrm{CA}-60 \mathrm{~s}$,

$5.25 \% \mathrm{NaOCl}-120 \mathrm{~s}$.

Each of the liquids listed was inserted into the canal through a beveled $0.4 \times 19 \mathrm{~mm}$ needle, using reciprocating motion in small portions $(1 \mathrm{~mL})$. Each portion was activated with ultrasounds for $5 \mathrm{~s}$ using an ISO 35 spreader (VDW $\mathrm{GmbH}$ ) on the E1 tip of a Smart Piezo scaler (Mectron $\mathrm{SpA}$, Carasco, Italy). Each fluid exchange and activation cycle lasted $15 \mathrm{~s}$; therefore, the stages lasting $30 \mathrm{~s}, 60 \mathrm{~s}$ and $120 \mathrm{~s}$ were completed in 2,4 and 8 cycles of irrigationactivation, respectively.

Distilled water was applied in each group at the end of irrigation. After the irrigation of the root canals, the roots were incised along the axis using a separator with diamond coating on both sides under constant water and air cooling. During the incision, special attention was paid not to damage the canal walls. Then the roots were split using a chisel, obtaining 2 parts with visible canal walls.

The prepared specimens were observed using a Nikon Eclipse LV100 microscope (Nikon Corp., Tokyo, Japan) at $\times 200-500$ magnification. The canals of both split root parts were analyzed on 3 levels: coronal $(10 \mathrm{~mm}$ from the apex), medial (6 $\mathrm{mm}$ from the apex) and apical ( $2 \mathrm{~mm}$ from the apex). Each observation with a manual change of the height of the microscope platform (the distance from the lens) was aimed at determining the limit points of a sharp image of the given portion of the specimen. The determined values were then entered into 
NIS-Elements Advanced Research software (Nikon Instruments Inc., Melville, USA). A computer-controlled digital camera took $30-90$ pictures in $2560 \times 1920$ resolution while moving the specimen away from the lens in 0.5 -micrometer increments within the determined limits. The aggregate images of the canal dentin surface were obtained by superimposing several dozen pictures with an aggregate resolution of $0.14 \mu \mathrm{m} /$ pixel, whereas the computer software used an algorithm for selective superimposition of parts of images with sharp contours. The obtained images were saved to graphic files, encoded and analyzed. We modified the system described by Prado et al. to assess the effectiveness of smear layer removal $^{5}$ (Fig. 1):

1 - no smear layer;

2 - a small area covered with the smear layer, most of the tubules open;

3 - the smear layer covering most of the examined dentin surface;

4 - the smear layer covering the dentin surface completely.
Two independent observers conducted a blind analysis and assessment of encoded groups. If the specimen assessment was not unanimous, the observers reached a consensus. The collected data was saved to a database, decoded and then subjected to statistical analysis using Kruskal-Wallis and Kendall's tau tests, with the threshold of statistical significance set at $\mathrm{p} \leq 0.05$.

\section{Results}

We did not observe $100 \%$ effective smear layer removal in any of the study groups. In the control group, all of the specimens were contaminated with smear layers. The most effective removal of the smear layer was observed in groups 3 and 4. No statistically significant differences were found between groups 3 and 4 in any of the 3 parts of the root canals $(p=0)$. The differences between groups 3 and 4 and groups 1 and 2 were statistically significant in the apical and medial sections of the root canals (apical: $\mathrm{p}=0.006$; medial: $\mathrm{p}=0.019$ ).
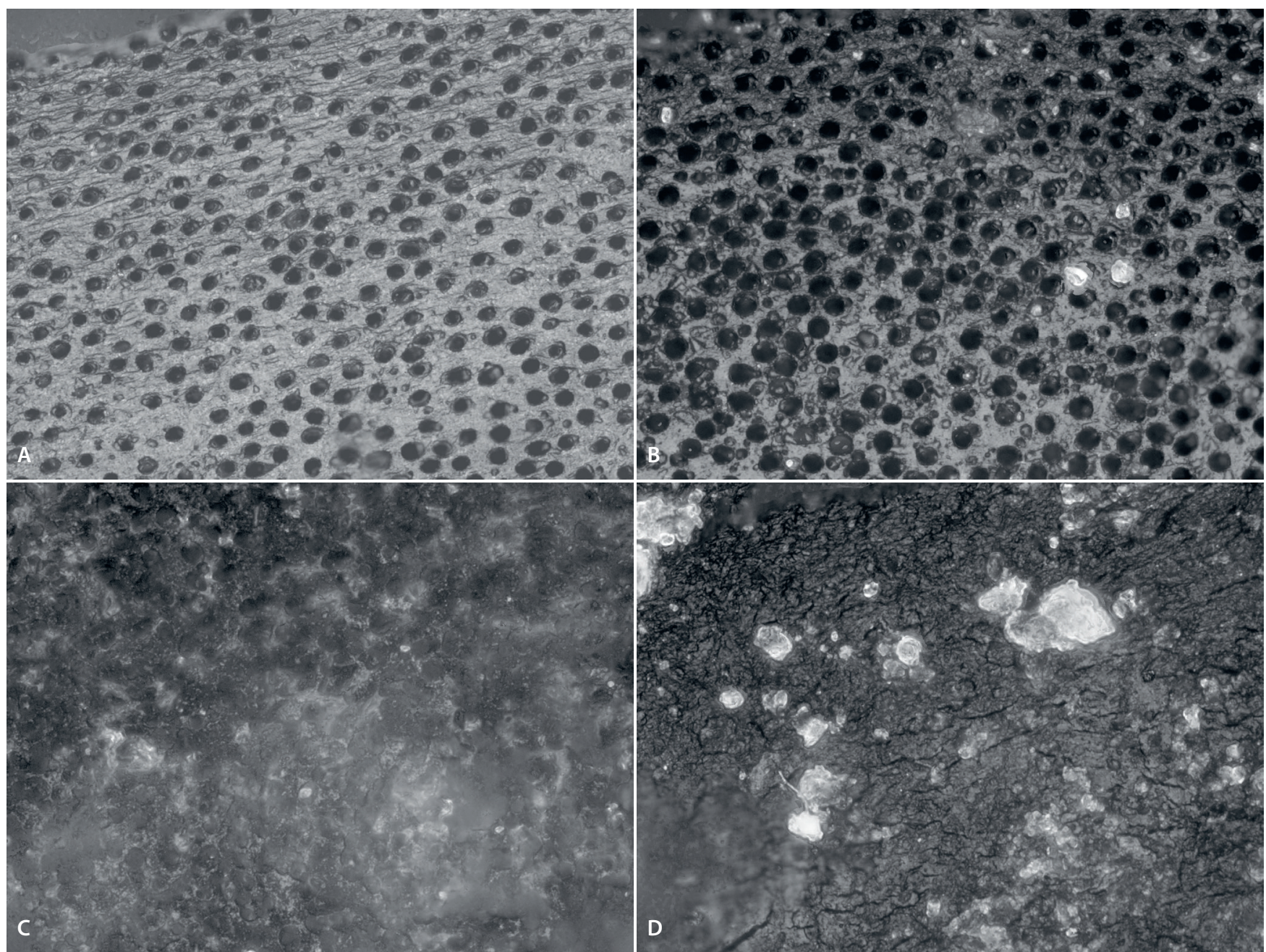

Fig. 1. Exemplary images of the scoring calculation method: A - score 1 (clean canal wall with no smear layer); B - score 2 (most of the tubules opened with small, partial area covered with smear layer); C - score 3 (most of the surface covered with smear layer with few tubules opened); D - score 4 (surface completely covered with smear layer) 
Table 1. Examples of the scoring calculation method: (a) score 1: a clean canal wall with no smear layer; (b) score 2: most of the tubules opened with a small partial area covered with the smear layer; (c) score 3: most of the surface covered with the smear layer, with few tubules opened; (d) score 4: surface completely covered with the smear layer

\begin{tabular}{|c|c|c|c|c|c|c|c|c|c|c|c|c|}
\hline \multirow{2}{*}{ Score } & \multicolumn{4}{|c|}{ Apical } & \multicolumn{4}{|c|}{ Middle } & \multicolumn{4}{|c|}{ Coronal } \\
\hline & group 1 & group 2 & group 3 & group 4 & group 1 & group 2 & group 3 & group 4 & group 1 & group 2 & group 3 & group 4 \\
\hline Score 1 & 8 & 10 & 16 & 16 & 11 & 12 & 17 & 18 & 14 & 15 & 18 & 18 \\
\hline Score 2 & 8 & 7 & 4 & 4 & 6 & 6 & 3 & 2 & 4 & 4 & 2 & 2 \\
\hline Score 3 & 4 & 3 & 0 & 0 & 3 & 2 & 0 & 0 & 2 & 1 & 0 & 0 \\
\hline Score 4 & 0 & 0 & 0 & 0 & 0 & 0 & 0 & 0 & 0 & 0 & 0 & 0 \\
\hline
\end{tabular}

However, in the coronal part, no statistically significant differences were found $(\mathrm{p}=0.22)$. The data is presented in Table 1.

\section{Discussion}

Examination using SEM is most commonly used to assess the effectiveness of smear layer removal and to observe the dentin surface. While preparing specimens for such tests, it is necessary to dehydrate and macerate the specimen in alcohol in increasing concentrations (observation in high vacuum conditions) and apply a nanolayer of metal. As a result of these processes, the specimen is damaged permanently, as all the organic structures become denaturated and collapse due to dehydration. Another disadvantage of SEM is the fact that it is impossible to use the specimen again for further tests. Therefore, assessing the exposed matrix of collagen fibers after chelating agents is impossible in a standard SEM test. ${ }^{1,2,6}$ Tay et al. used an additional stage of impregnating specimens in silazane before applying the metal, which allowed different images to be obtained than the ones observed in standard SEM. ${ }^{6}$ It is likely that SEM observations of dentin after the use of chelating agents did not constitute a complete reflection of the dentin surface. Collapsed organic structures, such as exposed collagen, are coated with a nanolayer of metal; therefore, it is not an actual image of the dentin after demineralization. ${ }^{6}$ Exposed collagen fibers are not hybridized by sealers and can undergo bacterial and enzymatic degradation. ${ }^{7}$ The conclusion is that $\mathrm{NaOCl}$ should be used after chelating agents to dissolve the exposed protein matrix and ensure penetration into open dentinal tubules. ${ }^{7,10-12}$ Therefore, in this study, each irrigation protocol was completed with $\mathrm{NaOCl}$.

Due to the numerous flaws of SEM, attempts were made to take different images of dentin. De-Deus et al. suggested the use of a computer-controlled optical microscope as an alternative to SEM. In comparison with SEM, examination with an optical microscope is possible without any additional chemical processing of the specimens. ${ }^{2-4}$ In their studies, De-Deus et al. observed the speed of smear layer removal and dentin demineralization using various chelating agents. This study employed a similar method of obtaining images of the surface of dentin. Sharp, clear pictures can be obtained by selective superimposition of several dozen stacks taken at various distances from the specimen, at $50 \mu \mathrm{m}$ intervals. One of the biggest advantages of this method is its low cost and low time consumption. The main limitation is its $\times 500-1000$ magnification, which is too low to observe nanostructures. However, it is sufficient for analyzing the effectiveness of smear layer removal.

Smear layer removal is one of the important stages of root canal irrigation. Sodium hypochlorite is used to remove the organic components of the smear layer, while the inorganic components are removed using chelating agents of various strengths and concentrations. To this day, there is no consensus regarding the best sequence, concentration and time of canal irrigation with various liquids. ${ }^{1-5,9}$ The most commonly used chelating agents are EDTA and CA. De-Deus et al. analyzed peracetic acid and etidronic acid (HEBP) compared to EDTA., ${ }^{3,4}$ Their studies showed that HEBP is a much weaker chelating agent than EDTA, but that a $2.25 \%$ concentration of peracetic acid can be used as an alternative to 17\% EDTA. Our study employed $40 \%$ CA, which is a very strong chelating agent. The recommended time of root canal irrigation with $17 \%$ EDTA is $120-180 \mathrm{~s}$; for $40 \%$ CA, the time can be shorter due to the higher reactivity of the acid. This study used 4 irrigation protocols. The aggregate irrigation time with CA was $60 \mathrm{~s}$ (groups 1 and 3) or $120 \mathrm{~s}$ (groups 2 and 4). In groups 3 and 4, the canals were irrigated with CA in 2 cycles, $30 \mathrm{~s}$ and $60 \mathrm{~s}$, respectively. Between the chelating agent irrigation cycles, the canals were irrigated with $5.25 \% \mathrm{NaOCl}$ in order to dissolve exposed organic substances (organic components of the smear layer, exposed collagen). During the alternate irrigation, interactions between the agents used must be taken into consideration. In the case of irrigation with alternating $\mathrm{NaOCl}$ and chelating agents, larger volumes of liquids should be used, as the infused liquid becomes inactivated due to chemical reactions with the other liquid in the canal.

This study took these interactions into account and used short infusions with short ultrasound activation in order to ensure the best distribution of the liquids in the endodontic system. A study by Karunakaran et al. showed that ultrasound activation increases the efficiency and effectiveness of root canal irrigation. Thanks to alternating acoustic waves and vibrations, the liquids penetrate the canal grooves and irregularities. ${ }^{11} \mathrm{~A}$ very large number of studies concerning the effectiveness of smear layer removal did not employ 
ultrasound activation. ${ }^{1-6,9}$ Therefore, it is difficult to relate those studies to clinical situations, as ultrasound activation is a standard procedure in modern endodontics. In most studies, the least effective smear layer removal was obtained in the apical section. ${ }^{5,9,12-15}$ In this study, we obtained a very high degree of smear layer removal in the apical section in groups 3 and 4, probably due to ultrasound activation and alternating application of the chelating agent and $\mathrm{NaOCl}$. It is interesting that there were no differences between groups 3 and 4 despite the fact that the aggregate irrigation time with CA was $60 \mathrm{~s}$ in group 3 and $120 \mathrm{~s}$ in group 4.

In this situation, we rejected the null hypothesis as the study showed that smear layer removal is facilitated not by the duration of irrigation with a chelating agent, but rather by alternate irrigation with hypochlorite. Irrigation with hypochlorite probably increases the effectiveness of the subsequent CA irrigation cycle. This may be due to exposure of the organic structures in the deeper parts of the smear layer and the dentin (collagen) during the $1^{\text {st }}$ irrigation cycle with the chelating agent. Irrigation with $\mathrm{NaOCl}$ dissolves organic substances, ensuring a better reaction between the subsequent application of the chelating agent and the canal wall. This explains the statistically significant differences between group 2 (irrigation with the chelating agent in a single 120-second cycle) and group 3 (irrigation with the chelating agent in 2 30-second cycles). The shorter duration of irrigation with the chelating agent was somewhat compensated by better penetration of the $2^{\text {nd }}$ cycle of irrigation with the chelating agent, following hypochlorite. This phenomenon requires further studies employing other methods to fully understand the nature of changes in the morphology of the surface of dentin caused by irrigation.

To sum up this study (and its limitations), we can state that irrigation with $40 \% \mathrm{CA}$ alternating with $5.25 \% \mathrm{NaOCl}$ was the most effective in removing the smear layer.

\section{ORCID iDs}

Wojciech Wilkoński (1) https://orcid.org/0000-0001-7205-5586 Lidia Jamróz-Wilkońska (1) https://orcid.org/0000-0003-0637-1104 Szczepan Zapotoczny (1) https://orcid.org/0000-0001-6662-7621 Janusz Opiła (1) https://orcid.org/0000-0003-1179-1920 Jerzy Krupiński (1) https://orcid.org/0000-0001-7112-8704 Jolanta Pytko-Polończyk (1) https://orcid.org/0000-0002-5700-2387

\section{References}

1. De-Deus G, Paciornik S, Pinho Mauricio MH, Prioli R. Real-time atomic force microscopy of root dentine during demineralization when subjected to chelating agents. Int Endod J. 2006;39(9):683-692.

2. De-Deus G, Reis CM, Fidel RA, Fidel SR, Paciornik S. Co-site digital optical microscopy and image analysis: An approach to evaluate the process of dentine demineralization. Int Endod J. 2007;40(6):441-452.

3. De-Deus G, Zehnder M, Reis C, et al. Longitudinal co-site optical microscopy study on the chelating ability of etidronate and EDTA using a comparative single-tooth model. J Endod. 2008;34(1):71-75.

4. De-Deus G, Souza EM, Marins JR, Reis C, Paciornik S, Zehnder M. Smear layer dissolution by peracetic acid of low concentration. Int Endod J. 2011;44(6):485-490.

5. Prado M, Gusman H, Gomes BP, Simão RA. Scanning electron microscopic investigation of the effectiveness of phosphoric acid in smear layer removal when compared with EDTA and citric acid. J Endod. 2011;37(2):255-258.

6. Tay FR, Gutmann JL, Pashley DH. Microporous, demineralized collagen matrices in intact radicular dentin created by commonly used calciumdepleting endodontic irrigants. J Endod. 2007;33(9):1086-1090.

7. Tay FR, Hosoya Y, Loushine RJ, Pashley DH, Weller RN, Low DC. Ultrastructure of intraradicular dentin after irrigation with BioPure MTAD. II. The consequence of obturation with an epoxy resin-based sealer. J Endod. 2006;32(5):473-477.

8. Pawińska M, Szczurko G, Kierlo A, Sidun J. A laboratory study evaluating the $\mathrm{pH}$ of various modern root canal filling materials. Adv Clin Exp Med. 2017;26(3):387-392.

9. Khedmat S, Shokouhinejad N. Comparison of the efficacy of three chelating agents in smear layer removal. J Endod. 2008;34(5):599-602.

10. Bojar W, Marczewska J, Karwicka E, Anuszewska E. Cytotoxicity and mutagenicity of N2 cement: Root canal filling material. Adv Clin Exp Med. 2009;18(6):615-621.

11. Karunakaran JV, Kumar SS, Kumar M, Chandrasekhar S, Namitha D. The effects of various irrigating solutions on intra-radicular dentinal surface: A SEM analysis. J Pharm Bioallied Sci. 2012;4(2):S125-130.

12. Hasheminia SM, Birang R, Feizianfard M, Nasouri M. A comparative study of the removal of smear layer by two endodontic irrigants and Nd:YAG laser: A scanning electron microscopic study. ISRN Dent. 2012;2012:620951. doi:10.5402/2012/620951

13. Cavassim R, Leite FR, Zandim DL, Dantas AA, Rached RS, Sampaio JE. Influence of concentration, time and method of application of citric acid and sodium citrate in root conditioning. J App/ Oral Sci. 2012; 20(3):376-383.

14. Andrabi SM, Kumar A, Kumar Tewari R, Kumar Mishra S, Iftekhar H. An in vitro SEM study on the effectiveness of smear layer removal of four different irrigations. Iran Endod J. 2012;7(4):171-176.

15. Wu L, Mu Y, Deng X, Zhang S, Zhou D. Comparison of the effect of four decalcifying agents combined with $60^{\circ} \mathrm{C} 3 \%$ sodium hypochlorite on smear layer removal. J Endod. 2012;38(3):381-384. 